\title{
The New Story of Changing \\ Exploring Dichotomies in the Field of Organizational Change
}

\author{
Bruskin, Signe
}

Document Version

Final published version

Published in:

International Journal of Knowledge, Culture \& Change in Organizations: Annual Review

DOI:

10.18848/1447-9524/CGP/v19i01/7-16

Publication date:

2019

\section{License \\ CC BY-NC-ND}

Citation for published version (APA):

Bruskin, S. (2019). The New Story of Changing: Exploring Dichotomies in the Field of Organizational Change. International Journal of Knowledge, Culture \& Change in Organizations: Annual Review, 19(1), 7-16. https://doi.org/10.18848/1447-9524/CGP/v19i01/7-16

Link to publication in CBS Research Portal

\section{General rights}

Copyright and moral rights for the publications made accessible in the public portal are retained by the authors and/or other copyright owners and it is a condition of accessing publications that users recognise and abide by the legal requirements associated with these rights.

Take down policy

If you believe that this document breaches copyright please contact us (research.lib@cbs.dk) providing details, and we will remove access to the work immediately and investigate your claim. 


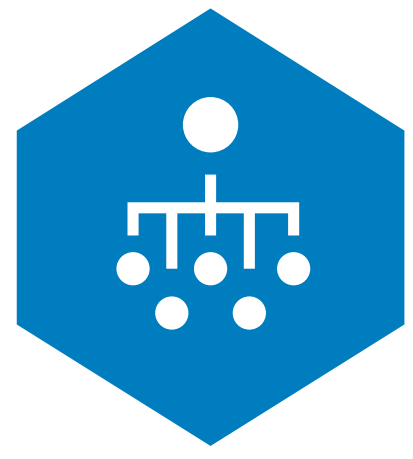

The International Journal of

Knowledge, Culture, and Change Management: Annual Review

The New Story of Changing

Exploring Dichotomies in the Field of Organizational Change

SIGNE BRUSKIN 
EDITOR

Ross Brinkert, Penn State Abington, USA

ACTING DIRECTOR OF PUBLISHING

Jeremy Boehme, Common Ground Research Networks, USA

\section{MANAGING EDITOR}

Helen Repp, Common Ground Research Networks, USA

\section{ADVISORY BOARD}

The Organization Studies Research Network recognizes the contribution of many in the evolution of the Research Network. The principal role of the Advisory Board has been, and is, to drive the overall intellectual direction of the Research Network.

A full list of members can be found at

https://organization-studies.com/about/advisory-board.

\section{PEER REVIEW}

Articles published in The International Journal of Knowledge, Culture and Change Management: Annual Review are peer reviewed using a two-way anonymous peer review model. Reviewers are active participants of the Organization Studies Research Network or a thematically related Research Network. The publisher, editors, reviewers, and authors all agree upon the following standards of expected ethical behavior, which are based on the Committee on Publication Ethics (COPE) Core Practices. More information can be found at: https://organization-studies.com/journals/model.

\section{ARTICLE SUBMISSION}

The International Journal of Knowledge, Culture, and Change Management: Annual Review publishes annually (December). To find out more about the submission process, please visit

https://organization-studies.com/journals/call-for-papers.

\section{ABSTRACTING AND INDEXING}

For a full list of databases in which this journal is indexed, please visit https://organization-studies.com/journals/collection.

\section{RESEARCH NETWORK MEMBERSHIP}

Authors in The International Journal of Knowledge, Culture, and Change Management: Annual Review are members of the Organization Studies Research Network or a thematically related Research Network. Members receive access to journal content. To find out more, visit https://organization-studies.com/about/become-a-member.

\section{SUBSCRIPTIONS}

The International Journal of Knowledge, Culture, and Change Management: Annual Review is available in electronic and print formats. Subscribe to gain access to content from the current year and the entire backlist. Contact us at cgscholar.com/cg_support.

University of Illinois Research Park

2001 South First Street, Suite 202

Champaign, IL 61820 USA

$\mathrm{Ph}:+1-217-328-0405$

https://cgnetworks.org

The International Journal of Knowledge, Culture, and Change Management: Annual Review is a peer-reviewed, scholarly journal.

\section{COPYRIGHT}

(C) 2020 (individual papers), the author(s)

(C) 2020 (selection and editorial matter),

Common Ground Research Networks

\section{(이요 $\odot$}

Some Rights Reserved.

Public Licensed Material: Available under the terms and conditions of the Creative Commons Attribution-NonCommercial-NoDerivatives 4.0 International Public License (CC BY-NC-ND 4.0). The use of this material is permitted for non-commercial use provided the creator(s) and publisher receive attribution. No derivatives of this version are permitted. Official terms of this public license apply as indicated here: https://creativecommons.org/licenses/by-nc-nd/4.0/legalcode

\section{ORDERING}

Single articles and issues are available from the journal bookstore at https://cgscholar.com/bookstore.

\section{HYBRID OPEN ACCESS}

The International Journal of Knowledge, Culture, and Change Management: Annual Review is Hybrid Open Access, meaning authors can choose to make their articles open access. This allows their work to reach an even wider audience, broadening the dissemination of their research. To find out more, please visit

https://organization-studies.com/journals/open-access-articles.

\section{DISCLAIMER}

The authors, editors, and publisher will not accept any legal this publication. The publisher makes no warranty, express or implied, with respect to the material contained herein. responsibility for any errors or omissions that may have been made in

\section{Crossref}




\title{
The New Story of Changing: Exploring Dichotomies in the Field of Organizational Change
}

\author{
Signe Bruskin, Copenhagen Business School, Denmark
}

\begin{abstract}
This article theoretically explores and unpacks existing dichotomies in the field of organizational change. By revisiting the dichotomies "planned-emergent change" and "major-minor change," the article finds that only relying on one extreme of a dichotomy gives a too simplistic view on change in organizations. Instead, the article proceeds by combining the two dichotomies and further explores the exceptions: the studies that do not only rely on one extreme of the dichotomies but instead moves along dichotomies. Based on the findings, the article suggests that future studies of organizational changes take an emic approach and study organizational changes in situ in order to capture the vividness of organizational changes.
\end{abstract}

Keywords: Organizational Change, Dichotomies, Planned, Emergent, Major, Minor

\section{Introduction}

$\mathrm{T}$ The field of organizational change is widespread and has a long history. Scholars have for decades written about the topic and the way organizational change is defined and viewed varies within the field, which scholars have tried to map out (e.g., Armenakis and Bedeian 1999; Burke 2002; Smith and Graetz 2011; Todnem 2005; van de Ven and Poole 1995, 2005; Weick and Quinn 1999). The aim of this article is not to present an exhaustive review of the literature on organizational change, but to explore some of the most central dichotomies within the field. Traditionally, the field has been characterized by dichotomies such as plannedemergent change (e.g., Beer and Nohria 2000) and episodic-continuous change (e.g., Weick and Quinn 1999) in order to capture the different views of organizational change. Dichotomies symbolize a division into two mutually exclusive or contradictory groups or entities, why studies of change in the field of organizational change are characterized by extremes.

Even though the field of organizational change has developed over the last decades, it is surprising that practitioners still tend to draw on more traditional theories of organizational change, such as Kotter's (1996) eight-step change model, which reflects only one end of a dichotomy, namely the planned change. This article revisits some of the most central dichotomies to explore whether these contain unexplored possibilities. Hence, the intention is to unpack the potential of rewriting the story of organizational change, so it better captures the vividness of organizational changes. Grounded in this intention, the article pursues the research question: How can dichotomies in the field of organizational change be reconsidered in order to capture the vividness of change in organizations?

After exploring two central dichotomies in the field of organizational change, the article proceeds by combining them and revisiting existing studies to unfold these combinations. Two gaps emerge, which are discussed in the final section of the article, the first being empirical studies that cannot be placed within one single category but instead move along a dichotomy; the second being empirical studies of minor organizational changes, in particular within the field of process studies.

\section{The Dichotomy of Planned-Emergent Change}

The most significant dichotomy within the field of organizational change is between scholars viewing organizational changes as either planned or emergent (e.g., Beer and Nohria 2000). Hence, the dichotomy is about to what extent organizational change is deliberate. Another quite

The International Journal of Knowledge, Culture, and Change Management: Annual Review Volume 19, Issue 1, 2020, https://organization-studies.com

(C) Common Ground Research Networks, Signe Bruskin,

Some Rights Reserved, CC BY-NC-ND 4.0). Permissions: cgscholar.com/cg_support

ISSN: 1447-9524 (Print): ISSN: 1447-9575 (Online)

https://doi.org/10.18848/1447-9524/CGP/v19i01/7-16 (Article) 
similar distinction made in the theoretical field of organizational change is planned-unplanned change (e.g., Poole and van de Ven 2004): however, there are some differences.

The former, a planned view, originates from a rational assumption that organizational change can be planned and managed through stage-models. This is the most traditional view on organizational changes and most often this conceptualization is attributed to the works of Kurt Lewin (1947) and his three-stage model of change-Unfreezing, Moving, and Freezing (Cummings, Bridgman, and Brown 2016). These stage-models represent rather simple, linear, and practical ways to understand organizational changes, which characterize the main view of the planned perspective. Some of the main contributors to the planned view are Kanter et al. (1992), Kotter (1996), Luecke (2003), and Nadler and Nadler (1998). All of these scholars have developed multistep models with a desired end state. Because of its normative and controllable nature, this approach to change is the most distinct in practice. Within the planned view, organizational changes are initiated from the top, as a top-down process, led by managers through a linear process. Thus, changes are seen as episodic and "off the-shelf standardized solutions" (Weick 2000, 232), and the aim becomes to get back to stability. Successful organizational changes are often ascribed to the manager in charge of the change. Opposite, because of the belief that organizational changes can be managed and controlled, an unwanted outcome of the change will often be due to errors in executing the planned steps: "Skipping steps creates only the illusion of speed and never produces a satisfying result" (Kotter 1999, 76). In other words, the planned view builds on a leader-centric approach to organizational changes, where the manager bears a big responsibility for the outcome of an organizational change and the planned steps in the process are seen as sequential.

In contrast to the planned view, the emergent view defines change as continuous and ongoing. Weick $(2000,223)$ makes the argument that "emergent, continuous change forms the infrastructure that determines whether planned, episodic change will succeed or fail." This quote emphasizes how the two perspectives are fundamentally different and that emergent change occurs without a priori intentions as is the case with planned change. A study of continuous change is the one by Brown and Eisenhardt (1997). Based on an inductive study of change in the IT industry, they argue that the important changes happening in organizations are continuous and incremental as opposed to episodic. However, their view on continuous and incremental change leans against planned change, when they state that "many firms compete by changing continuously" (Brown and Eisenhardt 1997, 1), thus, making it somehow different from emergent change, grounded in the assumption of emergent change as the opposite of planned change on the dichotomy. What is also worth noticing in the quote by Weick $(2000,223)$ is that emergent and planned change in his view are not only two opposite ends of a dichotomy but can also be considered together. Similarly, Poole and van de Ven (2004) argue that a strategic planned change might occur in an organization already changing because of factors out of the control of the management, the unplanned or emergent changes. The intersection of these emergent and planned changes together shapes the organization.

Drawing on the work done by Lewin (1947), a slightly moderated sequence in an emergent view would be Freeze, Rebalance, Unfreeze (Weick and Quinn 1999). This is grounded in the assumption that the starting point must be to freeze continuous change by making a disrupted sequence visible. To rebalance is to reinterpret or resequence steps so they unfold with fewer blockages. Lastly, to unfreeze is to resume emergent change in ways that are not attentive to local changes (Weick 2000). By that, emergent change moves the focus of attention in the direction of smaller changes, adaptions, and adjustments in routines, moving beyond what can be managed, choreographed, scripted, or controlled, and is instead a force in its own right (Poole and van de Ven 2004). 


\section{The Dichotomy of Major-Minor Changes}

Another central dichotomy within the field of organizational change is major-minor changes. This dichotomy is about the scale of an organizational change and has not often been explicitly unfolded or discussed in the literature. However, most studies can be classified as focusing on either minor or major organizational changes. Sandberg and Tsoukas (2015) have a somewhat similar classification of sensemaking studies of organizational changes, when they argue that sensemaking is triggered by minor or major events.

In this article, major organizational changes are the ones that are radical to the organization, as major and minor are relative terms. These are, for example, mergers, acquisitions, strategic restructurings, organizational crisis, etc. What characterizes this type of organizational change is the extent of influence on the organization, where the change in itself influences a major part of the organization. Historically, the field of organizational change has been occupied with major organizational changes. One reason for this might be grounded in, for example, how the Cambridge Dictionary defines organizational change as "a process in which a large company or organization changes its working methods or aims, for example in order to develop and deal with new situations or markets." " Grounded in that definition, organizational change becomes not only planned and intentional but also something that is remarkable or visible both internally and externally. Thus, the prevalent definition of organizational change is that it is a major change to the organization. This might explain why most empirical studies have been concerned with major organizational changes.

Similar to how Lewin's (1947) three-stage model of change has been fundamental for the development of step models within the field of organizational change, so has his argumentation of what change is. One interpretation of Lewin's definition of organizational change can be found in Oreg and Berson $(2019,273)$ : "Organizational change refers to the transition of the organization from one state to another (Lewin, 1951)." By that, organizational change becomes something that moves the organization from one state to another; hence, making it a major change to the organization. Examples of empirical studies of major organizational changes are Lüscher and Lewis (2008), studying organizational restructurings; and Monin et al. (2013) and Reynolds (2015), studying mergers and acquisitions.

At the other end of the dichotomy are studies focusing on minor organizational changes. When organizational changes are part of everyday work practices or organizational routines, they can be categorized as minor organizational changes. A group of scholars grounded in process philosophy builds on the belief that "[m]icroscopic change reflects the actual becoming of things" (Tsoukas and Chia 2002, 580). The argument here is that to investigate changes, attention must be paid to microprocesses, because this is where change originates from. In line with that, March (1981) and Brown et al. (2015) have emphasized that attention must be paid to mundane experiences and events, because they are contingent to the overall process of change. Thus, they emphasize how studies of organizational change must be focused on the minor organizational changes, which are part of the mundane and everyday work activities of the organization, to unpack processes of change.

This argument is further unfolded within process philosophy with the central assumption that everyday work activities cannot be separated from routines, as a lot of work done in organizations is performed through routines. As March $(1981,564)$ states: "in its fundamental structure a theory of organizational change should not be remarkably different from a theory of ordinary action," hereby, emphasizing how studying minor organizational changes is a matter of studying everyday work activities and organizational routines. This might explain why the field of organizational change has mainly been focusing on major organizational change, because studies of minor organizational changes are as much a study of everyday work activities or organizational routines. Empirical examples of studies of minor organizational changes are

\footnotetext{
${ }^{1}$ https://dictionary.cambridge.org/dictionary/english/organizational-change
} 
Dittrich, Guérard, and Seidl (2016), where they examine the role of reflective talk in routine changes; and Patriotta and Gruber (2015), who explore how newsmakers at a US television station make sense of and adjust to planned and unexpected events on a daily basis.

\section{Combining the Two Dichotomies}

To unfold the two dichotomies in more detail, and to unpack how existing empirical studies fit into these dichotomies, this article proceeds by exploring how the two dichotomies can be combined. Figure 1 is a simple illustration of the combination of the two dichotomies of plannedemergent and major-minor organizational changes, which will be further unfolded below. The empirical examples included are all within the field of process studies, thus theoretically closely related, to illustrate the nuances between the four categories.

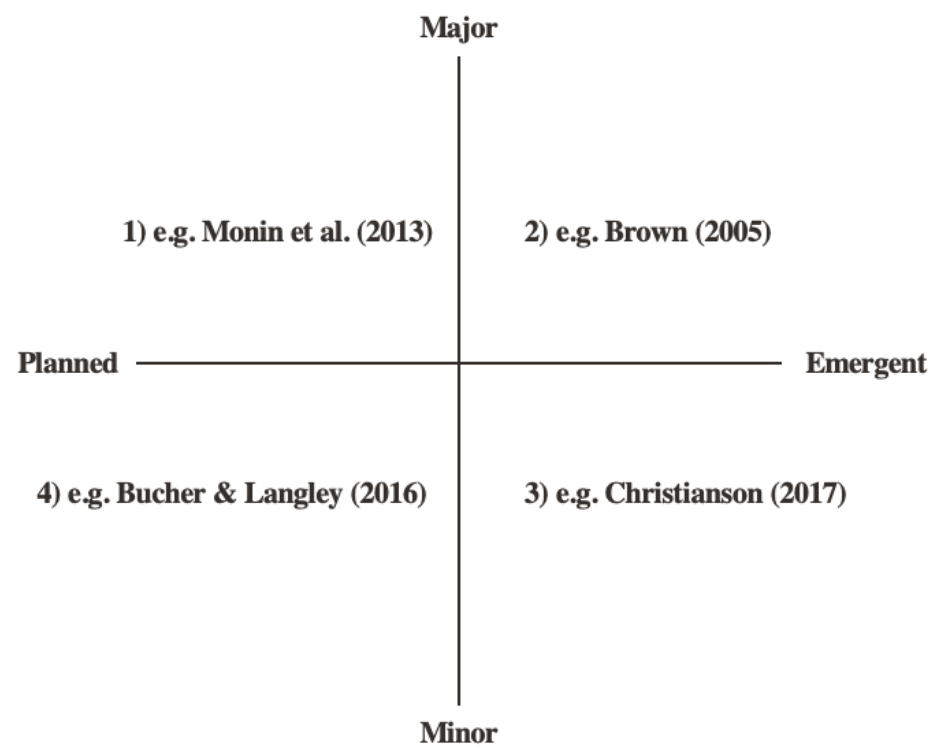

Figure 1: The Combination of the Dichotomies Planned-Emergent and Major-Minor Changes Source: Bruskin 2020

The first group of studies concerns organizational changes, which are major and planned, and represents the most studies in the field of organizational change. Major and planned organizational changes are often strategic ones, such as mergers and acquisitions (e.g., Monin et al. 2013). In particular, a number of empirical studies have been concerned with the organizational members' reactions to organizational changes, most often by looking at major planned changes (e.g., Bartunek et al. 2006; Oreg et al. 2018; Oreg, Michel, and Todnem 2013; Soderberg 2003).

When organizational changes are major and emergent, they often have similarities with organizational crisis, where the changes interrupt organizational activities. This is due to the fact that major emergent changes are often characterized by ambiguity, confusion, and feelings of disorientation for the involved organizational members and so are organizational crises (Maitlis and Sonenshein 2010). Brown's (2005) study of the collapse of Baring Bank as the result of fraud is an example of emergent major organizational change.

Organizational changes as part of everyday work practices can be categorized as minor organizational changes, either planned or emergent. An example of an empirical study of minor emergent changes is that of Orlikowski (1996), who focused on the situated micro level changes that actors enact over time as they make sense of and act in the world. In this particular study, the 
example of minor emergent changes is new technology changing everyday organizational routines, when organizational members appropriate the new technology into their work practices or when organizational members respond to unanticipated breakdowns. Another example of an empirical study of minor emergent changes is Christianson (2017), who unpacks "updating" as the process of revising provisional sensemaking to incorporate new cues in the case of unexpected events, namely broken equipment.

Minor planned changes can also be identified as changes in everyday organizational activities and routines. Feldman (2000) and Tsoukas and Chia (2002) have argued that routines are not as stable and unchanging as is so often presented in organization studies. Instead, scholars have pointed out how the internal dynamic of a routine is a source of change in and of itself (e.g., Feldman and Pentland 2003; Howard-Grenville et al. 2016). Examples of a minor planned change can be a new hiring process, changing the routines as part of the recruitment process, as was one of the examples in Feldman (2000); or a planned initiative to change patient processes in hospitals, examined by Bucher and Langley (2016).

Looking broadly at process studies of organizational change, the majority have been on major rather than minor changes; only a few have studied minor organizational changes as smaller disturbances in ongoing routine activities (Brown, Colville, and Pye 2015; Sandberg and Tsoukas 2015). Instead, most research has been centered on major organizational changes such as a mergers or acquisitions.

\section{The Exceptions}

In this article, I have explored two dichotomies in the field of organizational change, namely planned-emergent change and major-minor change. In addition, I have explored a combination of the two dichotomies grounded in a discussion of existing studies. However, some studies do not fit into these combinations.

The first empirical study to explore is by Orlikowski and Hofman (1997). In their study of technology-based change, they build an improvisational model of change management to recognize the importance of different types of change, namely, anticipated, emergent, and opportunity-based. By that, they include both the anticipated changes, which are planned changes, and the emergent ones. Thus, they incorporate both ends of the dichotomy plannedemergent in the same model, breaking with the classic idea of relying on only one end of the dichotomy.

Building further on their line of thought and the above-mentioned argument made by Weick (2000) about how planned and emergent changes are interlinked, I will argue that we need to consider the two extremes together instead of only one of them. In doing so, organizational changes can be unfolded in more nuances. Think of this example: A reorganization (planned change) is called off because the managing director is being dismissed by the company without notice (emergent change). In the planned view, the reorganization would be the organizational change, which would have ended the day it was called off; whereas the emergent view would only view the managing director leaving the company as a change in the organization, because the reorganization never created any changes in the organization due to the fact it never took place. However, if we draw on both ends of the dichotomy, we get to see the two organizational changes as interlinked. By bringing the two perspectives together, we see more nuances in how organizational changes unfold and by that, it enriches our understanding of change in organizations. If we draw on only one of the extremes, we end up with a too simple view of organizational changes.

Another example, which does not fit into only one of the four combinations in Figure 1, is the study by Bartunek, Huang, and Walsh (2008). The study focuses on minor emergent changes, when an individual decides to leave the organization. However, in all three cases included in the study, the individual leaving led to collective turnover, revealing how a minor emergent change can lead to a major emergent change. This particular study shows the value in not studying only 
the minor emergent change or only the major emergent change, but instead how they are interlinked.

Other empirical studies also examine the movement along dichotomies rather than staying within one extreme. Examples of studies linking major planned changes and minor planned changes are Kellogg $(2009,2018)$, which show how institutional changes influence everyday work practices in two US hospitals. These empirical examples show the value of not categorizing studies into one end of a dichotomy, but instead moving along dichotomies to explore how the changes are interlinked.

\section{Discussion}

So far, this article has explored and challenged existing dichotomies in the field of organizational change. I found that while most studies of organizational change focus on one of the four categories, a few empirical studies move between them. I also found that most process studies of organizational change examine major planned changes. The fact that most studies can be categorized into one of the four categories indicates that the potential associated with studies with a change perspective, which move between categories, is not sufficiently exploited. In addition, few studies focus on minor organizational changes. In sum, existing studies in the field have created a too simplistic view of organizational changes, which do not capture the vividness of organizational changes.

Therefore, this article proceeds by discussing the two gaps identified above. First, discussion centers on the lack of empirical studies of minor organizational changes, in particular in the field of process studies. Second, I explore the potential of studying organizational changes that move between the categories.

\section{Studies of Minor Organizational Changes}

As the findings of this article show, the field of process studies lacks empirical studies of minor organizational changes. In particular, this is supported by scholars pointing at the lack of sensemaking studies focusing on the more mundane forms of organizational change (e.g., Brown et al. 2015; Gioia and Mehra 1996; Powell and Rerup 2017; Sandberg and Tsoukas 2015; Tsoukas and Chia 2002).

One of the differences between sensemaking of minor and major changes, which might also be one of the reasons why the field is lacking studies of minor changes, is the triggers of the sensemaking. Triggering episodes such as mergers are easier to identify and, thereby, easier to design a study around. Further, salient cues such as public announcements of mergers are easier to capture than when sensemaking is immanent; thus, not triggered by episodes and happening without the organizational members being aware (Sandberg and Tsoukas 2015, 2019). In particular, when the cues are not salient, they are even harder to collect later in the process, because they might have disappeared or been forgotten by organizational members. Thus, when sensemaking is immanent or at least not triggered by major episodes, it becomes harder for the researcher to study.

One way to overcome this challenge is to approach change from within (Tsoukas and Chia 2002). Thus, it becomes essential to study the minor organizational changes while they are unfolding in order to unpack how organizational members are experiencing the changes. This calls for empirical studies studying organizational changes through an emic approach (Sandberg and Tsoukas 2019). When studying organizational change through an emic approach, the researcher studies from inside the primary world, thus making it possible to study how organizational members' sensemaking of organizational changes is accomplished. This is in contrast to an etic approach, where the researcher studies from the outside world. Here, the researcher studies how organizational members make deliberate sense of organizational changes, prompted by the researcher's queries. 
Further, there is a potential in capturing minor organizational changes by studying organizational members and changes in situ. Returning to the quote by March $(1981,564)$ included above, "a theory of organizational change should not be remarkably different from a theory of ordinary action," underpins the call for empirical studies of everyday work activities to capture the minor organizational changes. Studying organizational members in their everyday work situation creates a possibility of capturing the less salient cues. However, both the emic approach and studying in situ implies a more complex study than if organizational changes are studied through an etic approach, because the researcher must be there when the minor organizational changes are taking place.

\section{Studies of the Uncategorizable Changes}

This section aims at unpacking and discussing the studies of organizational changes that are impossible to categorize in Figure 1; hence, the studies moving along a dichotomy rather than staying within one of the extremes. I found that a number of empirical studies study organizational changes that move from one category to another; however, the field is lacking this kind of study. This is particularly interesting because these studies have an unexplored potential in unfolding organizational changes to a greater extent.

To capture organizational changes that move from one category to another calls for studies of changes that are not a priori determined. When organizational changes are a priori determined, the research is designed around already identified organizational changes. This type of study is often grounded in what I above define as an etic approach (Sandberg and Tsoukas 2019). Sandberg and Tsoukas $(2019,42)$ make this argument, elaborating on the etic approach: "In such an approach, sensemaking is likely to be viewed as a relatively well-bounded phenomenon (hence, inclined to be seen as episodic rather than ongoing): whose cognitionrelated and/or language-use-related properties may be abstracted and their associations studied in a systematic manner." This explains well how an etic approach limits the view of organizational changes to a well-bounded phenomenon that can be studied in a systematic manner, rather than being open to organizational changes moving along a change dichotomy.

However, to study organizational changes that are not a priori determined, it is again essential to enter the field through an open approach, being open to an emic definition of organizational change. This definition is not predefined but is continuously being constructed by the organizational members in the field. That implies that to capture organizational change, which is never a well-bounded phenomenon, it is essential to have an open approach throughout the research process. First, this is crucial in the process of collecting the data, e.g., asking open questions and not paying attention only to salient cues. Second, it is crucial in the process of analyzing the data, where a more inductive rather than deductive approach will support the researcher in staying open to the data, and the possibility of new emic definitions of organizational change can emerge. 


\section{Conclusion}

In this article, I have explored two central dichotomies in the field of organizational change, namely planned-emergent and major-minor. When combining the two, I found that a number of studies move between the categories; however, these were only few in number, which creates an unexplored potential of studying organizational changes that move along dichotomies. Moreover, I found that the field of process studies lacks empirical studies of minor organizational changes. Proceeding from the findings, the article paves the way for how to rewrite the story of changing by suggesting that future empirical studies focus on studying organizational changes in situ through an emic approach in order to close the gaps identified in the field, thus creating the possibility of capturing organizational changes to a greater extent.

\section{REFERENCES}

Armenakis, A. A., and A. G. Bedeian. 1999. "Organizational Change: A Review of Theory and Research in the 1990s." Journal of Management 25 (3): 293-315. https://doi.org/10.1177/014920639902500303.

Bartunek, J. M., Z. Huang, and I. J. Walsh. 2008. "The Development of a Process Model of Collective Turnover." Human Relations 61 (1): 5-38. https://doi.org/10.1177/0018726707085944.

Bartunek, J. M., D. M. Rousseau, J. W. Rudolph, and J. A. DePalma. 2006. "On the Receiving End." The Journal of Applied Behavioral Science 42 (2): 182-206.

Beer, M., and N. Nohria. 2000. Breaking the Code of Change. Cambridge, MA: Harvard Business Press.

Brown, A. 2005. "Making Sense of the Collapse of Barings Bank." Human Relations 58 (2): 1579-1604. https://doi.org/ 10.1177/0018726705061433

Brown, A. D., Colville, I., and Pye, A. 2015. "Making Sense of Sensemaking in Organization Studies." $\quad$ Organization $\quad$ Studies $36 \quad$ (2): https://doi.org/10.1177/0170840614559259.

Brown, Shona L. and Kathleen M. and Eisenhardt. 1997. "The Art of Continuous Change: Linking Complexity Theory and Time-Paced Evolution in Relentlessly Shifting Organizations." Administrative Science Quarterly $42 \quad$ (1): 1-34. https://doi.org/10.2307/2393807.

Bucher, S. and A. Langley. 2016 "The Interplay of Reflective and Experimental Spaces in Interrupting and Reorienting Routine Dynamics." Organization Science 27 (3): 594 613. https://doi.org/10.1287/orsc.2015.1041.

Burke, W. W. 2002. Organization Change: Theory and Practice. Thousand Oaks, CA: SAGE Publications, Inc.

Christianson, M. 2017. "More and Less Effective Updating: The Role of Trajectory Management in Making Sense Again." Administrative Science Quarterly 64 (1): 45-86. https://doi.org/https://doi.org/10.1177/0001839217750856.

Cummings, S., T. Bridgman, and K. Brown. 2016. "Unfreezing Change as Three Steps: Rethinking Kurt Lewin's Legacy For Change Management." Human Relations 69 (1): 33-60. https://doi.org/10.1177/0018726715577707.

Dittrich, K., S. Guérard, and D. Seidl. 2016. "Talking about Routines: The Role of Reflective Talk in Routine Change." Organization Science 27 (3): 678-97. https://doi.org/10.1287/orsc.2015.1024.

Feldman, M. 2000. "Organizational Routines as a Source of Continuous Change." Organization Science 11 (6): 611-29. https://doi.org/10.1287/orsc.11.6.611.12529. 
Feldman, M. and B. Pentland. 2003. "Reconceptualizing Organizational Routines as a Source of Flexibility and Change." Administrative Science Quarterly 48 (1): 94-118. https://doi.org/10.2307/3556620.

Gioia, D. A., A. and Mehra. 1996. "Review: Sensemaking in Organizations." The Academy of Management Review 21 (4): 1226-30. https://doi.org/10.2307/259169.

Howard-Grenville, J., C. Rerup, A. Langly, and H. Tsoukas. 2016. "Introduction." In Organizational Routines: How They Are Created, Maintained, and Changed, edited by J. Howard-Grenville, C. Rerup, A. Langly, and H. Tsoukas. Oxford, UK: Oxford University Press. https://doi.org/10.1093/acprof:oso/9780198759485.001.0001.

Kanter, R. M., B. Stein, and T. D. Jick. 1992. The Challenge of Organizational Change: How Companies Experience It and Leaders Guide It. New York: Free Press.

Kellogg, K. C. 2009. "Operating Room: Relational Spaces and Microinstitutional Change in Surgery." American Journal of Sociology $115 \quad$ (3): 657-711. https://doi.org/10.1086/603535.

Kellogg, K. C. 2018. "Subordinate Activation Tactics: Semi-professionals and Micro-level Institutional Change in Professional Organizations." Administrative Science Quarterly 64 (4): 1-48. https://doi.org/10.1177/0001839218804527.

Kotter, John P. 1996. Leading Change. Boston, MA: Harvard Business School Press. . 1999. John P. Kotter on What Leaders Really Do. Boston, MA: Harvard Business Review Press.

Lewin, K. 1947. "Frontiers in Group Dynamics: Concept, Method and Reality in Social Science; Social Equilibria and Social Change." Human Relations 1 (1): 5-41. https://doi.org/10.1177/001872674700100103.

Luecke, R. 2003. Managing Change and Transition. Boston, MA: Harvard Business School Press.

Lüscher, L. S., M. W. and Lewis. 2008. "Organizational Change and Managerial Sensemaking: Working through Paradox." The Academy of Management Journal 51 (2): 221-40. https://doi.org/10.2307/20159506.

Maitlis, S., and S Sonenshein. 2010. "Sensemaking in Crisis and Change: Inspiration and Insights from Weick (1988)." Journal of Management Studies 47 (3): 551-80. https://doi.org/10.1111/j.1467- 6486.2010.00908.x.

March, J. G. 1981. "Footnotes to Organizational Change.” Administrative Science Quarterly 26 (4): 563-77. https://doi.org/10.2307/2392340.

Monin, P., N. Noorderhaven, E. Vaara, and D. Kroon. 2013. "Giving Sense to and Making Sense of Justice in Postmerger Integration." Academy of Management Journal 56 (1): 256-84. https://doi.org/10.5465/amj.2010.0727.

Nadler, D. A., and M. B. Nadler. 1998. "The Success Syndrome.” Leader to Leader 1998 (7): 43-50. https://doi.org/10.1002/lt1.40619980712.

Oreg, S., J. M. Bartunek, G. Lee, and B. Do. 2018. “An Affect-based Model of Recipients' Responses to Organizational Change Events." Academy of Management Review 43 (1): 65-86. https://doi.org/10.5465/amr.2014.0335.

Oreg. S., and Y. Berson. 2019. "Leaders' Impact on Organizational Change: Bridging Theoretical and Methodological Chasms." Academy of Management Annals 13 (1): 272-307. https://doi.org/10.5465/annals.2016.0138.

Oreg, S., A. Michel, and R. Todnem. 2013. The Psychology of Organizational Change. Cambridge: Cambridge University Press. https://doi.org/10.1017/CBO9781139096690.

Orlikowski, W. J. 1996. "Improvising Organizational Transformation Over Time: A Situated Change Perspective." Information Systems Research 7 (1): 63-92. https://doi.org/10.1287/isre.7.1.63.

Orlikowski, W. J., and J. D. Hofman. 1997. "An Improvisational Model for Change Management: The Case of Groupware Technologies." Sloan Management Review 38 (2): $11-21$. 
Patriotta, G. and D. Gruber. 2015. "Newsmaking and Sensemaking: Navigating Temporal Transitions Between Planned and Unexpected Events." Organization Science 26 (6): 1574-1592. https://doi.org/10.1287/orsc.2015.1005.

Poole, M. S., and A. H. Van de Ven. 2004. Handbook of Organizational Change and Innovation. Oxford: Oxford University Press.

Powell, W. W., C. and Rerup. 2017. "Opening the Black Box: The Microfoundations of Institutions." In The Sage Handbook of Organizational Institutionalism, edited by R. Greenwood, C. Oliver, T. B. Lawrence, and R. E. Meyer, 311-37. Los Angeles: SAGE.

Reynolds, N. 2015. "Making Sense of New Technology during Organisational Change." New Technology, Work and Employment 30(2): 145-57. https://doi.org/10.1111/ntwe.12045.

Sandberg, J., H. and Tsoukas. 2015. "Making Sense of the Sensemaking Perspective: Its Constituents, Limitations, and Opportunities for Further Development." Journal of Organizational Behavior 36: 6-32. https://doi.org/10.1002/job.1937.

Sandberg, J., and H. Tsoukas. 2019. "Sensemaking Reconsidered: Towards a Broader Understanding through Phenomenology." Unpublished Paper Presented at Copenhagen Business School, Frederiksberg, Denmark.

Smith, A. C. T., and F. M. Graetz. 2011. Philosophies of Organizational Change. Cheltenham, UK: Edward Elgar Publishing. https://doi.org/10.4337/9780857932891.

Soderberg, A. 2003. "Sensegiving and sensemaking in Integration Processes: A Narrative Approach to the Study of an International Acquisition." In Narratives We Organize by: Narrative Approaches in Organization Studies, edited by B. Czarniawska and P. Gagliardi, 3-36. Amsterdam: John Benjamins Publishing Company.

Todnem, R. 2005. "Organisational Change Management: A Critical Review." Journal of Change Management 5 (4): 369-80. https://doi.org/10.1080/14697010500359250.

Tsoukas, H., and R. Chia. 2002. "On Organizational Becoming: Rethinking Organizational Change." Organization $\quad$ Science $13 \quad$ (5): https://doi.org/10.1287/orsc.13.5.567.7810.

Van de Ven, A. H., and M. S. Poole. 1995. "Explaining Development and Change in Organizations." The Academy of Management Review 20 (3): 510-40. https://doi.org/10.2307/258786.

2005. "Alternative Approaches for Studying Organizational Change.” Organization Studies 26 (9): 1377-1404. https://doi.org/10.1177/0170840605056907.

Weick, K. E. 2000. "Emergent Change as a Universal in Organizations." In Breaking the Code of Change, edited by M. Beer and N. Nohria, 223-42. Cambridge, MA: Harvard Business Press.

Weick, K. E., and R. E. Quinn. 1999. "Organizational Change and Development.” Annual Review of Psychology 50: 361-86. https://doi.org/10.1146/annurev.psych.50.1.361.

\section{ABOUT THE AUTHOR}

Signe Bruskin: Doctoral Researcher, Department of Organization, Copenhagen Business School, Copenhagen, Denmark 
The International Journal of Knowledge, Culture, and Change Management: Annual Review aims to create an intellectual frame of reference, and to support an interdisciplinary conversation examining the nature of the organization in all their forms and manifestations. Candidates for inclusion in this survey journal include works by invited contributors and top-ranked articles selected from thematic journals of the collection.
Four thematically focused journals also serve this Research Network:

- Change Management: An International Journal

- Knowledge Management: An International Journal

- Management Education: An International Journal

- Organizational Cultures: An International Journal

The International Journal of Knowledge, Culture, and Change Management: Annual Review is a peer-reviewed, scholarly journal. 